\title{
O impacto do esporte competitivo na escolha alimentar: narrativas de atletas de ginástica artística masculina
}

\author{
Anna Vitoria Rodrigues Renaux de Oliveira ${ }^{1}$ \\ Claudia Ridel Juzwiak (1) ${ }^{1}$ \\ Ricardo da Costa Padovani ${ }^{1}{ }^{1}$ \\ ${ }^{1}$ Universidade Federal de São Paulo - Campus Baixada Santista, SP, Brasil.
}

\begin{abstract}
Resumo
Esportes que supervalorizam a estética e o baixo peso corporal são indicados como os com mais incidência de comportamentos alimentares de risco. Diante disto, investigou-se o impacto do esporte competitivo na escolha alimentar de atletas de ginástica artística masculina e, para tanto, foram entrevistados quatro ginastas adultos do gênero masculino. Trata-se de um estudo transversal, com o uso das narrativas como abordagem metodológica. As entrevistas foram obtidas por meio de questões abertas e analisadas à luz da análise de conteúdo, evidenciando dois núcleos temáticos: "regras e estética" e "alimento como merecimento". Os resultados indicam que as escolhas alimentares destes atletas no período competitivo, são desprovidas de prazer, norteadas pela preocupação com a estética, pelo controle exercido pelo técnico e por autorregras. Após a competição, as escolhas aparecem relacionadas ao prazer, livre de regras e vistas como recompensa. Portanto, conclui-se a vulnerabilidade deste grupo às escolhas alimentares prejudiciais à saúde.
\end{abstract}

Palavras-chave: alto rendimento; esporte competitivo; ginástica artística.

\section{The impact of competitive sport on food choices: narratives of male artistic gymnastics athletes}

\begin{abstract}
In sports which overvalue aesthetics and low body weight athletes have a higher incidence of risky eating behavior. The aim of this study was to identify the impact of the sport environment on food choices of male artistic gymnastics athletes. Four adult male artistic gymnastics athletes were interviewed. It is a cross-sectional study, which used narratives as the methodological approach. The interviews were obtained through open-ended questions and were analyzed though the content analysis, evidencing two thematic nuclei: rules and aesthetic and food as merit. The results indicate that the food choices of these athletes, during the competitive period, are devoid of pleasure, guided by the concern about aesthetics, controlled by the coaches and self-rules. After competition, choices appear to be related to pleasure, free of rules and seen as reward. Therefore, we conclude the vulnerability of this group to harmful food choices.
\end{abstract}

Keywords: high performance; competitive sports; artistic gymnastics.

\section{El impacto del deporte competitivo en la elección alimentaria: narrativas de atletas de gimnasia artística masculina}

Resumen

Deportes que sobrevaloran la estética y el bajo peso corporal conducen a mayor incidencia de comportamientos alimentarios de riesgo. Se investigó el impacto del deporte competitivo en la elección alimentaria de atletas de gimnasia artística. Se entrevistaron cuatro gimnastas adultos, del género masculino. En este estudio transversal, se utilizó las narrativas como propuesta metodológica. Las entrevistas fueron obtenidas a través de preguntas abiertas y fueron analizadas a la luz del análisis de contenido, evidenciando dos núcleos temáticos: reglas y estética y alimento como merecimiento. Los resultados indican que las elecciones alimentarias de estos atletas, en el período competitivo, están desprovistas de placer, orientadas por la preocupación por la estética, el control ejercido por el técnico y las autorreglas. Después de la competición, las elecciones se relacionan con el placer, libre de reglas y consideradas como recompensa. Por lo tanto, se concluye la vulnerabilidad de este grupo a las opciones alimenticias perjudiciales para la salud.

Palabras clave: alto rendimento, deporte competitivo, gimnasia artística. 
Atingir níveis de excelência no esporte de alto rendimento exige do atleta um estilo de vida saudável, um corpo adaptado à modalidade esportiva escolhida, treinamentos específicos e contínuos, participações em competições, cumprimento de metas predefinidas e disciplina rigorosa (Weinberg \& Gould, 2017). Além disso, o cenário do esporte de alto rendimento pode ser um ampliador das pressões socioculturais motivadas pelo ideal de corpo magro e/ou forte. $\mathrm{Ou}$ seja, o ambiente atlético tem características peculiares que parecem potencializar o risco de surgimento de transtornos alimentares e insatisfação corporal nos atletas (Fortes \& Ferreira, 2011). Atletas apresentam, assim, grandes riscos de transtornos alimentares devido à pressão para alcançarem a composição corporal que otimize a performance e, em esportes nos quais a magreza confere uma vantagem competitiva, os riscos de transtornos alimentares se tornam ainda maiores, tanto para mulheres como para homens (Joy, Kussman \& Nattiv, 2016; Krentz \& Warschburger, 2011, 2013; Tan, Bloodworth, McNamee \& Hewitt, 2014).

As modalidades esportivas estéticas podem ser entendidas como aquelas que aliam gestos artísticos com música e coreografias à performance e exigem que os competidores tenham aparência corporal magra e flexibilidade. São caracterizadas pela presença de banca de juízes que avaliam o desempenho dos atletas conforme a técnica, a beleza do movimento, a dificuldade das acrobacias e a estética do atleta em situação de competição. A ginástica artística masculina enfatiza qualidades naturais do sexo- resistência e força-resultado de um corpo magro (com pouca gordura, mas musculoso) com baixa estatura, menor taxa de crescimento do que a população não atlética, maturação puberal tardia e capacidade de flexibilidade superior (DelašKalinski, Jelaska \& Knezević, 2017; Fortes, Almeida \& Ferreira, 2014; Fortes, Neves, Filgueiras, Almeida, \& Ferreira, 2013; Krentz \& Warschburger, 2011, 2013).

Como cada modalidade esportiva demanda características específicas para a composição e formato do corpo do atleta, estudos apontam (Bosi, Oliveira, Vieira \& Vigário, 2003; Díaz, Ceballos, Ramisa \& Fernández, 2012; Krentz \& Warschburger, 2011, 2013; Silva \& Gomes 2012; Tan et al., 2014) que esportes que supervalorizam a estética e o baixo peso corporal, inclusive utilizando-os como critérios para participação e obtenção de bons resultados em competições como acontece, por exemplo, na ginástica artística têm sido indicados como os de maior incidência de comportamentos alimentares de risco, bem como de transtornos do comportamento alimentar. Tal fato é confirmado nos estudos de Bortoleto, Bellotto e Costa
(2007) e de Fortes et al. (2013), quando apontam que a ginástica artística é um esporte que exige do atleta uma composição corporal específica, pois a forma e a aparência dos atletas são extremamente importantes e, por isso, as preocupações e as exigências estéticas frequentemente levam os ginastas a desenvolverem hábitos alimentares inadequados.

Outro aspecto é que as modalidades esportivas podem ser consideradas como tipicamente masculinas, femininas ou neutras. Neste cenário, a ginástica artística, caracterizada por movimentos acrobáticos e ginásticos é considerada na sociedade brasileira como uma prática tipicamente feminina, gerando um afastamento do público masculino (Tsukamoto \& Knijnik, 2008). Os autores destacam que, em função dessa concepção, crianças podem deixar de conhecer uma modalidade desafiadora e extremamente rica do ponto de vista motor. Ampliar o entendimento das especificidades das diferentes modalidades esportivas pode lançar luz para importantes aspectos da saúde física e mental dos atletas envolvidos na sua prática. Tais informações se revelam de grande importância para profissionais e estudiosos da área da saúde e do esporte.

Nesta perspectiva, Bratland-Sanda e SundgotBorgen (2012) ao realizarem um levantamento da literatura sobre os transtornos alimentares entre adolescentes e adultos atletas concluíram, entre outros achados, que a prevalência dos transtornos alimentares é maior entre atletas quando comparado com não atletas e entre mulheres atletas/não atletas quando comparadas com homens atletas/não atletas. As autoras apontam a influência da cultura do esporte na presença de comportamentos alimentares de risco e que é necessário ampliar o entendimento dos transtornos alimentares entre atletas do gênero feminino e masculino. Destacam que a compreensão das diferenças de gênero se revela de fundamental importância para o desenvolvimento de programas de prevenção (Bratland-Sanda \& SundgotBorgen, 2012).

Ao realizarem uma análise da produção científica específica da nutrição aplicada à ginástica artística, Bortoleto et al. (2007) apontaram predominância de estudos de ginastas do sexo feminino, visto que há maior interesse do público feminino por esta modalidade esportiva. De toda produção científica levantada pelos autores, $10,5 \%$ descreve os hábitos alimentares dos ginastas, sendo que a sua totalidade trata de ginastas do sexo feminino. No entanto, há estudos que apontam a ocorrência de hábitos alimentares não saudáveis em atletas do sexo masculino, principalmente nos esportes que envolvem rígido controle de peso (Fortes, Ferreira \& Almeida, 2012). Uma recente revisão sistemática 
que analisou a produção científica sobre insatisfação corporal e comportamentos alimentares de risco para transtornos alimentares em adolescentes atletas de esportes estéticos, não identificou estudos que considerassem modalidades esportivas estéticas cuja amostra se constituísse apenas de indivíduos do gênero masculino (Neves, Meirelles, Carvalho \& Ferreira, 2015).

Acredita-se que no complexo contexto do esporte de alto rendimento, influências culturais, familiares, midiáticas, do técnico, cobranças por melhores resultados, controlede massa corporal e também características da própria modalidade esportiva podem gerar sentimentos depreciativos em relação à aparência física e influenciar o comportamento alimentar dos atletas (Birkenhead \& Slater, 2015; Bratland-Sanda \& Sundgot-Borgen, 2012; Fortes et al., 2012, 2013; Krentz \& Warschburger, 2011; Pelly, Burkhart, \& Dunn, 2018). Como exposto por Silva e Gomes (2012), a relação entre as pressões sociais e esportivas e o desenvolvimento de comportamentos alimentares problemáticos no esporte é mediada por um conjunto de variáveis (por exemplo, processos de internalização, insatisfação corporal, afetos negativos, comportamentos de restrição e modelagem de comportamentos) que, em geral, representam fatores de risco para o desenvolvimento de problemas alimentares entre os atletas.

Diante dos poucos estudos que analisaram as influências do contexto esportivo e o consumo alimentar de ginastas do gênero masculino, o objetivo do presente estudo buscou identificar o impacto do esporte competitivo na escolha alimentar de atletas de ginástica artística masculina.

\section{Método}

\section{Desenho do estudo}

Trata-se de um estudo transversal, de abordagem qualitativa. É um recorte do estudo "Consumo alimentar de atletas - escolhas alimentares e a construção de uma cultura alimentar atlética", aprovado pelo Comitê de Ética em Pesquisa da Universidade Federal de São Paulo (UNIFESP).

\section{Participantes}

Participou do estudo a equipe adulta de ginástica artística masculina, composta por quatro atletas em transição de carreira, de um município da Região Metropolitana da Baixada Santista.Todos os participantes eram maiores de 18 anos, sendo 21 anos a idade mínima e 32 anos a idade máxima. O tempo de prática destes atletas na modalidade esportiva variou de
6 a 23 anos. Todos os atletas relataram conciliar a rotina de treinos e competições com outros compromissos, como trabalho ou estudos no ensino superior. Apenas um atleta ainda residia com a mãe, enquanto os outros moravam sozinhos ou com companheira.

\section{Instrumentos}

As narrativas foram obtidas através de entrevistas em profundidade, realizadas a partir de um roteiro com questões abertas norteadoras e de aprofundamento (para explorar temas que não emergissem naturalmente nas falas, mas que eram importante para responder aos objetivos do estudo). O roteiro foi criado especificamente para este estudo, a fim de permitir que se compreendesse o complexo contexto da alimentação dos atletas, assim como a sua relação com a comida e como se constituem suas vivências e sentidos (Bates, 2004; Minayo, 2014). As seguintes temáticas foram abordadas: ingresso no esporte competitivo, alterações na alimentação causadas pelo esporte competitivo, percepções sobre alimentação adequada para o atleta, dificuldades alimentares, mudança alimentar de acordo com a periodização, preocupações alimentares, estratégias alimentares, fatores que influenciam a sua escolha alimentar, influência da derrota e da vitória na alimentação e influência das relações pessoais na escolha alimentar. As entrevistas foram gravadas em áudio e transcritas verbatin. O tempo médio das entrevistas foi de 40 minutos.

\section{Procedimento de coleta e análise de dados}

Os atletas foram convidados no local de treinamento. Após a manifestação de interesse em participar da pesquisa, foi agendado horário para aplicação das entrevistas, as quais os atletas autorizaram que fossem gravadas. A assinatura do Termo de Consentimento Livre e Esclarecido formalizou a participação no estudo.

As entrevistas foram gravadas em áudio, transcritas e analisadas, inicialmente, a partir da realização de uma leitura flutuante. Posteriormente, foi feita a busca dos valores, crenças e representações dos indivíduos acerca do fenômeno a ser investigado. Foram empregados procedimentos exploratórios de modo a viabilizar o surgimento de núcleos temáticos.

Após a transcrição, cada entrevista foi identificada com código alfanumérico com a letra $\mathrm{P}$ seguida de um número diferente, indo do $\mathrm{P} 1$ ao $\mathrm{P} 4$. A preparação do material foi feita por meio do desmembramento e agrupamento das entrevistas de acordo com os tópicos e os temas suscitados, o que possibilitou, por conseguinte, a criação a posteriori de dois núcleos temáticos. Os dados foram tabulados de modo que o conjunto de 
informações correspondente a cada temática e suas respectivas respostas originassem relatórios específicos que pudessem ser individualmente interpretados e posteriormente analisados, correlacionando-os com a literatura existente sobre a temática e com as referências teóricas que nortearam a pesquisa. Portanto, a análise dos dados considerou os seguintes procedimentos: leitura exaustiva de cada entrevista, estabelecimento de núcleos temáticos, organização e análise do material segundo os núcleos temáticos e cotejamento dos conteúdos dos núcleos com a literatura existente sobre a temática e com as referências teóricas que nortearam a pesquisa (Minayo, 2014).

\section{Resultados e Discussão}

Os resultados das quatro entrevistas realizadas com os atletas são apresentados a partir da definição de dois núcleos temáticos que buscaram responder ao objetivo proposto, a saber: "regras e estética" e "alimento como merecimento".

\section{Regras e estética}

Ao relatarem as demandas físicas e psicológicas da ginástica artística, os participantes mencionaram privações, autorregras desenvolvidas para manutenção no esporte competitivo, características do esporte e o impacto da avaliação dos outros. Os relatos abaixo ilustram essas demandas:

"[...] eu tô na semana da competição, eu tô tentando comer um pouco menos pra ficar um pouco mais leve na competição [...] a gente procura estar na competição um pouco mais magro" (P2, comunicação pessoal, 9 fev. 2015).

"[...] quando eu engordo é bem nítido [...] então quando eu coloco o short, e é curto o short da ginástica, né? Então, e ficar sem camiseta e o pneuzinho fica pra fora [...] ai o técnico já vê isso e fala 'tá comendo brigadeiro demais, né?' Ai ele dá uma apertada" (P1, comunicação pessoal, 17 nov. 2014).

"Agora, quando eu estou nesses dois ou três meses antes da competição que eu tenho que baixar o peso e manter [...] Ai sim, eu procuro fazer um planejamento [...] Eu faço meio que uma lista assim de opções pra fazer me alimentar daquele jeito" (P4, comunicação pessoal, 09 fev, 2015).

Os relatos deixam evidente a presença de regras rígidas estabelecidas pelos próprios atletas para estarem dentro dos padrões exigidos pelo esporte. Para manterem o corpo magro e forte, valorizado pela ginástica artística, os atletas desenvolvem autorregras alimentares rígidas no sentido de evitar possíveis "erros" que prejudiquem o desempenho esportivo. É interessante observar que a preocupação dos atletas está pautada em atingir o corpo e a performance desejada, e não no impacto que a adoção de restrições alimentares pode ter para a saúde física e mental. Ao adotar uma regra o indivíduo pode tornar-se insensível às contingências às quais está exposto. Nesta perspectiva, o comportamento passa a ficar sob o controle das variáveis descritas pela regra (Paracampo, Reis \& Teixeira, 2005)

Deve-se considerar ainda, a influência das características da modalidade esportiva na modelação de padrões cognitivos e comportamentais daqueles que escolhem determinado esporte. Nesta direção, estudos indicam que modalidades esportivas que enfatizam a estética e formas corporais atléticas podem aumentar o risco de surgimento de comportamentos alimentares inadequados (Fortes \& Ferreira, 2011; Silva \& Gomes, 2012).

O ambiente atlético de modalidades esportivas que preconizam o baixo peso corporal parece potencializar o risco de surgimento de transtornos alimentares nos atletas. Alguns destes fatores são pressão de treinadores e pais, anseio por melhores resultados, vestimentas que salientam a forma corporal, ênfase dada à magreza e perda de peso corporal (Bosi et al., 2003; Fortes \& Ferreira, 2011). Ainda no que se refere aos efeitos da necessidade de aprovação, cabe refletir que a posição do atleta frente à demanda da modalidade pode estar alinhada aos rígidos padrões parentais de desempenho e aprovação social que foram significativos na construção do processo de subjetivação e, consequentemente, na sua forma de lidar com as demandas da realidade.

A ginástica artística é um esporte que exige do atleta uma composição corporal específica, já que a forma e a aparência dos atletas são extremamente importantes e, por isso, as preocupações e exigências estéticas nas competições muitas vezes levam os ginastas a desenvolverem hábitos nutricionais inadequados e a seguirem dietas rígidas, podendo resultar em uma baixa ingestão energética ao longo do dia (Bortoleto et al., 2007; Fortes, Ferreira, \& Almeida, 2014). De acordo com o estudo de Martínez Sanz, Urdampilleta, Micó e Soriano (2012), uma das práticas alimentares inadequadas mais recorrentes dos atletas de esportes considerados de maior risco é a restrição calórica extrema. Para diminuir a quantidade de calorias do dia, é comum que estes atletas não façam algumas 
refeições, como o café da manhã e o jantar, no dia anterior da competição.

Ainda em relação ao controle alimentar nos momentos da competição, os relatos a seguir deixam evidente o processo de adaptação às exigências da modalidade, o que não significa necessariamente cuidado à saúde física e mental. $\mathrm{O}$ esporte competitivo exige disciplina e comprometimento na rotina de treinamentos, o que pode levar o atleta a ter uma vida social com restrições. Com o objetivo de não quebrar as regras alimentares que os mantêm no padrão corporal desejado pelo esporte, evitar ambientes com estímulos para o comportamento alimentar pode ser uma estratégia, portanto, o alimento configura-se como punição na medida em que retira reforçadores da vida do atleta. Os relatos a seguir ilustram privações vividas pelos entrevistados ao adotarem regras alimentares rígidas no período competitivo.

"É dificil, é dificil, tem que ter muito foco [...] tem que colocar na cabeça 'não, eu não vou comer e pronto' e é difícil. [...] eu tenho que chegar na competição e mostrar o meu melhor, né? Não posso chegar gordo [...] então tem que treinar bastante e segurar um pouco a boca" ( $\mathrm{P} 2$, comunicação pessoal, 9 fev. 2015).

"Por exemplo, a família chama para comer.. normalmente eu não vou [...] já chegou o caso de o pessoal me chamar pra comer um X-picanha, um lanchão gigante assim, e eu levar um caqui para comer, mas só para ir junto e para não ficar sozinho" (P1, comunicação pessoal, 17 nov. 2014).

"[...] eu não como nada, eu vou pro treino sem comer nada, ai eu volto, almoço e procuro não comer muito, eu almoço pra me manter no mínimo satisfeito, ai eu vou pra competição [...]" (P2, comunicação pessoal, 9 nov. 2015).

"No dia da competição é o mínimo possível, é uma salada, é uma carne branca [...] e é isso, o mínimo possivel, assim, de carboidrato, de tudo assim, eu corto bastante" (P1, comunicação pessoal, 17 nov. 2014).

Fortes et al., (2013) sugerem que a ansiedade gerada pelas competições pode predispor as ginastas a restrições alimentares. Pode-se supor que o mesmo acontece aos ginastas do sexo masculino, uma vez que vivenciam o mesmo contexto em que se valoriza um corpo magro - e no caso deles, ao mesmo tempo forte - além de usarem vestimentas que evidenciam o corpo.
É possível inferir que na alimentação, ao contrário da competição, o atleta tem controle da situação. Por exemplo, ele pode escolher entre comer e não comer; na competição, o atleta não tem garantias se sairá vitorioso e/ou apresentará a performance almejada. Nesta perspectiva, o controle da dieta alimentar no momento que antecede a competição pode estar associado a crenças disfuncionais desenvolvidas e, muitas vezes, reforçadas no ambiente esportivo.

A literatura aponta que a insatisfação corporal, comum na ginástica, é outro fator facilitador da restrição alimentar. Evidências apontam que aproximadamente $50 \%$ das atletas apresentam níveis elevados de insatisfação corporal, tornando a restrição alimentar comum no âmbito esportivo. Outro estudo sugere que os comportamentos alimentares restritivos são os mais adotados entre as ginastas e atletas de outras modalidades estéticas. Aproximadamente 50\% das atletas utilizam a restrição alimentar para reduzir ou manter o peso corporal (Fortes \& Ferreira, 2012; 2014).

A insatisfação corporal diz respeito à depreciação que o sujeito tem de sua aparência física e está associada a significativas consequências psicológicas, como a baixa autoestima e a depressão. Autores apontam que atletas de esportes que preconizam baixo percentual de gordura e baixo peso corporal podem apresentar maior risco de desenvolver sintomas depressivos (Fortes \& Ferreira, 2011). Como indicadores de comportamentos relacionados à insatisfação corporal, Lavender e Anderson (2010) destacam a atividade física em excesso, dietas extremas, uso de esteroides e anabolizantes, e outros comportamentos mal adaptativos associados com o peso e o formato.

É importante salientar que a maioria dos estudos foi realizada com atletas do sexo feminino, observandose escassez de estudos realizados com atletas do sexo masculino. Portanto, é importante que sejam feitos mais estudos especificamente com a população masculina de atletas, principalmente com aqueles inseridos em modalidades estéticas. Na última década surgiram inúmeras pesquisas sobre a insatisfação corporal e comportamentos associados em homens, o que revelou uma quantidade significativa de homens que sofrem com a preocupação de sua imagem corporal (Lavender \& Anderson, 2010). A imagem corporal é um fenômeno biopsicossocial que diz respeito à representação mental do corpo e é constituído por inúmeros elementos, um desses é a insatisfação corporal. A insatisfação corporal, por sua vez, é um aspecto que não deve ser ignorado, já que é considerado sintoma de primeira ordem no desencadeamento dos transtornos alimentares (Fortes \& Ferreira, 2011). É possível observar nos relatos 
dos participantes do presente estudo, que os atletas não estavam satisfeitos com o próprio corpo, já que é explicito o desejo de manter-se magro e, em menor proporção, de obter mais músculos.

Diante da escassa literatura sobre a autoimagem e a insatisfação corporal de atletas de alto rendimento, principalmente em atletas do sexo masculino, Jürgensen, Padovani, D’Avila, Daniel e Juzwiak (2014) realizaram um estudo com 53 atletas brasileiros do sexo masculino, de diferentes esportes e constataram que $83 \%$ destes atletas desejavam ter uma silhueta maior à custa de massa muscular, enquanto $28,3 \%$ desejavam ter uma silhueta menor. Os autores do estudo concluíram que a elevada insatisfação corporal e o desejo de silhuetas mais fortes sugerem uma condição psíquica que pode afetar as escolhas alimentares destes atletas. O resultado do estudo de Fortes e Ferreira (2014) reforça essa evidência ao concluir que a insatisfação corporal esteve associada aos comportamentos de risco para transtornos alimentares nos atletas do gênero masculino.

Conforme evidenciado nos depoimentos de alguns entrevistados, a influência do treinador nas escolhas alimentares deste grupo de ginastas vai ao encontro de estudos que também abordam a relação entre treinador e atletas de esportes estéticos.

“[...] se visualmente ele (o técnico) estivesse vendo que você está gordo, começa: 'Ahh tem que ir pra $70 \mathrm{~kg}$. Ai chegou nos $70 \mathrm{~kg}$, olhou, está bonito? Está. Não, não está, vai pra $69 \mathrm{~kg}$. E assim era, não tinha estudo não" (P4, comunicação pessoal, 9 fev. 2015).

"Ele (o treinador) vê que a pessoa tá mais cheinha e começa a falar que tem que começar a ver a alimentação, que deve tá errada [...]” (P3, comunicação pessoal, 18 set. 2014).

"A cobrança dele é em relação ao corpo, se ele vê que você tá um pouquinho fora de forma, ele pega no pé, tipo, 'ah tá gordinho, né?'” (P1, comunicação pessoal, 17 nov. 2014).

"[...] meu treinador começou a cobrar o peso [...] foi quando ele começou a falar que eu comecei a pesquisar um pouco mais e mudar meus hábitos [...] porque a gente se pesava todo dia sabe, então eu comecei a me preocupar [...]" (P2, comunicação pessoal, 9 fev. 2015).

A influência dos treinadores é mais significativa em esportes de categoria de peso (Pelly et al., 2018) e esportes que preconizam o baixo peso corporal e supervalorizam a estética, como a ginástica artística, uma vez que a aparência é vista como um critério para a obtenção de bons resultados nas competições (Bosi et al., 2003). Juzwiak e Ancona-Lopez (2004) ao pesquisarem técnicos brasileiros de diversas modalidades esportivas, incluindo a ginástica artística, concluíram que $92 \%$ deles, atuando com essa modalidade, recomendam práticas alimentares para controle de peso. Além disso, Silva e Gomes (2012) apontam a existência de estudos que sugerem relação entre os comentários depreciativos dos treinadores a respeito da aparência física dos atletas e a tendência destes de usarem métodos de controle de peso pouco saudáveis e evidenciarem sintomas de transtornos alimentares. Nesse sentido, o estudo de Fortes, Filgueiras, Neves, Almeida e Ferreira (2014) apontou que esportistas do sexo feminino com humor negativo elevado podem estar mais susceptíveis à influência ambiental para controlarem os tipos e as quantidades de alimentos que costumam ingerir. A pressão imposta por treinadores para adoção de estética magra é considerada tão intensa, que muitas ginastas associam a atenuação da gordura corporal com a maximização do desempenho, assim, ganham importância as recomendações de alimentação não realizadas por nutricionistas, e sim pelos treinadores. No entanto, eles podem não dispor de informações adequadas e induzir crenças erradas sobre a alimentação adequada para atletas (Fortes et al., 2014; Martínez Sanz et al., 2012).

Ainda sobre a relação entre treinador e atleta, uma investigação a respeito da percepção de treinadores brasileiros da elite da ginástica artística sobre o conceito de força psicológica constatou que estes técnicos consideram um ginasta com força psicológica aquele que, entre outras atribuições, consegue controlar o peso e manter-se focado apesar dos atrativos do mundo fora do ginásio (Rodrigues, Dias, Corte-Real, \& Fonseca, 2014). Portanto, ao longo da discussão deste primeiro núcleo temático, fica evidente o quanto o contexto da ginastica artística apresenta potenciais estímulos desencadeadores de comportamentos alimentares de risco.

\section{Alimento como merecimento}

Nota-se que nos períodos de descanso ou diminuição da carga de treino, as escolhas alimentares aparecem relacionadas ao prazer, ao livre controle de regras e o alimento é visto como uma recompensa. No momento posterior à competição, o alimento que não podia ser consumido no período competitivo, torna-se uma gratificação para os atletas, tanto para comemorar as vitórias do esporte como para buscar conforto após 
uma falha ou derrota. Os atletas rompem com suas dietas restritas diante de uma frustração ou de uma conquista e uma nova regra emerge, a do alimento como merecimento. A seguir, os relatos mostram como o alimento é visto pelos atletas como fonte de prazer e recompensa no período pós-competitivo.

"[...] eu comia à vontade, assim, não pensava nem um pouquinho no meu corpo, na minha alimentação, só comia o que era gostoso" (P2, comunicação pessoal, 09 fev, 2015).

"[...] e quando vence, ai eu como também (risos), só que não tão com aquela culpa [...]" (P3, comunicação pessoal, 18 set. 2014).

“[...] Se é o último dia que eu competi, eu vou fazer aquela janta merecida, né? E se foi mal, também vou descontar na comida [...] depois da competição eu costumo fazer aquela refeição um pouco mais: 'Ufa, passou' [...]" (P4, comunicação pessoal, 9 fev. 2015).

"[...] ganhando ou perdendo, a gente dá uma folguinha [...] eu como uma pizza, sabe? Depois que passa a competição e não tem competição por perto dai a gente meio que relaxa." (P2, comunicação pessoal, 9 fev, 2015).

$\mathrm{O}$ alimento que não podia ser consumido no período competitivo torna-se uma gratificação para os atletas, tanto para comemorar as vitórias do esporte como para buscar conforto após uma derrota ou erro, ou seja, os atletas rompem com suas dietas restritas diante de uma frustração ou de uma conquista. Segundo Witt Huberts, Evers e Ridder (2014), as pessoas têm a tendência a atender seus desejos, mas só o fazem quando a situação permite, quando há uma justificativa que as permita flexibilizar suas regras pessoais. Nessa perspectiva, os relatos apresentados no presente estudo permitem observar que os atletas sentem vontade de consumir alimentos mais prazerosos durante o período competitivo, mas não cedem aos seus desejos, pois a situação não permite. No entanto, seus desejos são atendidos depois de uma competição, afinal, a situação justifica o consumo desses alimentos tentadores. Um interessante estudo citado também por Witt Huberts et al. (2014) sugere que as pessoas que usam seus esforços, conquistas e restrições como justificativas, optam por escolhas alimentares mais prazerosas e tentadoras, pois acreditam que seus esforços ultrapassaram seus limites.

Estudos apontam que o estado psicológico pode influenciar as escolhas alimentares e produzir desejos por um alimento específico (Birkenhead \& Slater, 2015; Mela, 2001; Troisi, Gabriel, Derrick, \& Geisler, 2015). Neste caso, o consumo deste alimento pode atenuar o desconforto emocional produzido por uma determinação situação. Esses apontamentos são confirmados nos relatos dos atletas que buscam no alimento o alívio da tensão, tanto na vitória, como também da frustração, na derrota. Alguns estudos apontam que os indivíduos tendem a controlar emoções negativas através do consumo alimentar (Bernardi, Cichelero, \& Vitolo, 2005; Macht, 2008). O estudo de Segato (2009) com velejadores verificou a relação entre consumo alimentar e estresse pós-regata. Entre os achados, verificou-se a relação entre o consumo de gorduras, a raiva e a fadiga antes da regata e o consumo de carboidratos e os níveis de fadiga tanto antes como após a regata.

A ingestão de alimentos específicos pode ser utilizada também como uma estratégia de autorregulação do humor. Dessa forma, alimentos frequentemente assumem função de aliviar sensações desagradáveis decorrentes de derrotas, falhas e resultados abaixo da expectativa, conforme pode ser observado nos trechos destacados a seguir:

"[...] têm aqueles dias que a gente tá meio bravo com tudo, então a gente come, então quero que se dane, então a gente come qualquer coisa [...]" (P3, comunicação pessoal, 18 set. 2014).

"Eu acho que quando é meio frustrante, quando você não atinge o que você quer, pelo menos eu, eu meio que não ligo mais por um tempo, assim, eu vou comer mesmo [...] aí eu começo a comer besteira" (P3, comunicação pessoal, 18 set. 2015).

A rotina fora do período de competições, por sua vez, é percebida como menos aversiva e, portanto, mais prazerosa. É possível observar que as dietas restritivas adotadas durante o período competitivo para alcançar um corpo magro não são consideradas nos períodos de diminuição de carga de treino e descanso, e as escolhas alimentares destes atletas deixam de ser governadas por regras e passam a ser influenciadas pelo desejo e pela disponibilidade do alimento. Neste momento, a alimentação deixa de ser influenciada por regras tanto autoimpostas como impostas por outras pessoas. Estudos afirmam que há uma associação entre restrição alimentar e alimentação exagerada, ou seja, indivíduos que adotam dietas rígidas são mais susceptíveis a comer exageradamente por um período (Birkenhead \& Slater, 2015; Mela, 2001). Tal constatação da autora reflete a realidade dos atletas 
descrita neste trabalho: um período intenso de treinos, competições e restrição alimentar seguido por um período de descanso e alimentação sem regras, com mais prazer e menos culpa.

“[...] você não tá indo todo dia pro ginásio, você acaba esquecendo a alimentação e sempre volta com aqueles quilinhos a mais, né?"(P1, comunicação pessoal, 17 nov. 2014).

"Então, eu não fico naquela neura de, por exemplo, se tem pizza à noite, vamos comer pizza... até quando der pra comer. É calórico, mas não estou nem aí. Mas, ai entro na rotina de novo. Mas normalmente, fora de temporada, sem competições, eu dou uma boa relaxada." (P4, comunicação pessoal, 9 fev. 2015).

“[...] se perde também é a mesma coisa [...] não me importo muito, não sou tão focado na alimentação assim, só durante o periodo competitivo, depois eu acho que eu largo um pouco" (P2, comunicação pessoal, 9 fev. 2015).

"Ah! normalmente muda. Normalmente eu estou meio que nem aí... vou aproveitar [...] mas no fim de semana eu como uma pizza, se tiver refrigerante, eu bebo refrigerante, e como besteira [...]" (P4, comunicação pessoal, 9 fev. 2015).

Estudos (Mela, 2001; Troisi et al., 2015) apontam que também há uma relação entre alimento e contexto, e essa relação pode ser determinada por convenções sociais e individuais. Esta mesma relação torna-se integrada a um sistema de sinais que podem motivar os desejos por comer alimentos específicos em circunstâncias específicas. A relação entre alimento e contexto determinada por regras sociais e individuais é bem notável no discurso dos ginastas, visto que a alimentação no contexto competitivo é marcada pelas regras dos treinadores e pela cultura da modalidade esportiva; o período pós-competitivo é marcado por uma alimentação sem regras, envolvendo alimentos considerados "besteiras" ou "proibidos".

A mesma autora sugere que a interrupção da restrição acontece quando alguma situação suspende sua imposição de restringir a alimentação. Os participantes do presente estudo, por exemplo, suspendem a restrição alimentar quando estão longe dos rígidos controles estéticos presentes no contexto competitivo. Desse modo, é liberado um desejo de comer que estava escondido, e normalmente esse desejo envolve comer uma grande quantidade de comida ou consumir sua comida preferida, cuja composição nutricional pode ser inadequada para atletas. Esse comportamento alimentar ocorre quando há aumento de estímulos externos (a visualização e o cheiro do alimento, por exemplo) e quando o indivíduo se encontra em uma dieta monótona, desse modo, a probabilidade de o indivíduo comer indiscriminadamente aumenta.

Pode-se, portanto, supor que o desenvolvimento de crenças relacionadas ao alimento como merecimento entre atletas de modalidades nas quais os parâmetros da modalidade estão pautados no baixo peso corporal e estética, se apresenta como uma espécie de contra controle de um ambiente marcado por sinalizadores diversos de punição. Nesse momento, a representação do ato de transgredir a regra vem acompanhado por emoções e afetos diversos, como por exemplo, satisfação, alegria, e também a raiva.

\section{Considerações finais}

A análise das narrativas deste grupo de ginastas possibilitou uma importante reflexão sobre vulnerabilidade dos atletas de ginástica artística masculina às escolhas alimentares que podem prejudicar a saúde e interferir na performance atlética. Nas contingências da rotina de treinamentos e competições, a escolha alimentar aparece relacionada à preocupação com a estética, à influência do técnico e ao estabelecimento de dietas restritas através de autorregras. Por outro lado, quando distantes dos estímulos do contexto competitivo, as escolhas alimentares aparecem relacionadas ao prazer e o alimento é visto como uma recompensa.

Foi identificada escassez de estudos sobre ginastas do sexo masculino e é ainda mais escassa a literatura que descreve os hábitos alimentares desse grupo esportivo, o que enfatiza a importância de novos estudos dentro dessa temática. Além disso, o número reduzido de participantes desta pesquisa pode ser considerado um fator limitante.

Considerando a relação polarizada que estes atletas estabelecem com o alimento - ora gratifica e conforta, ora pune e priva -, espera-se que o estudo tenha contribuído para novas reflexões sobre o impacto dos fatores psicológicos relacionados à escolha alimentar de atletas de modalidades esportivas que têm a massa corporal e a estética como importantes indicadores de desenvolvimento esportivo. Além disso, que auxilie profissionais da área da saúde e do esporte e incentive ações de natureza interdisciplinar no processo de promoção da qualidade de vida e do bem-estar psicossocial de atletas. 


\section{Contribuições individuais}

A primeira autora contribuiu na realização das entrevistas, na análise e discussão dos resultados, bem como na escrita do artigo. A segunda autora, coorientadora, concebeu a investigação, realizou as entrevistas, colaborou na análise e discussão dos resultados, bem como na escrita do artigo. O terceiro autor, orientador, participou da elaboração do estudo, na análise e discussão dos resultados e na escrita do artigo.

\section{Referências}

Bates, J. A. (2004). Use of narratives interviewing in everyday information behaviour research. Library \& Information Science Research, 26, 15-28. doi:10.1016/j.lisr.2003.11.003

Bosi, M. L. M., Oliveira, F. P., Vieira, R. S., \& Vigário, P. S. (2003). Comportamento alimentar e imagem corporal em atletas. Revista Brasileira de Medicina do Esporte, 9(6), 348-356. doi: 0.1590/S1517-86922003000600002

Bernardi, F., Cichelero, C., \& Vitolo, M. R. (2005). Comportamento de restrição alimentar e obesidade. Revista de Nutrição, 18(1), 85-93. doi:10.1590/S1415-52732005000100008

Birkenhead, K. L. \& Slater, G. (2015). A review of factors influencing athlete's food choices. Sports Medicine, 45(11), 1511-1522. doi: 10.1007/s40279-015-0372-1

Bortoleto, M. A. C, Bellotto, M. L., \& Costa, G. E. A. (2007). Nutrição esportiva aplicada à ginástica artística: sistematização da produção científica. O Mundo da Saúde, 31(4), 521-529. (DOI INEXISTENTE)

DelašKalinski, S., Jelaska, I., \& Knezević, N. (2017). Age effects among elite male gymnasts. Acta Kinesiologica, 2 , 84-89. (DOI INEXISTENTE)

Díaz, J. D., Ceballos, I. D., Ramisa, A. V., \& Fernández, O. D. (2012). Prevención y detección de los trastornos de alimentación en deportistas de alto rendimiento (CAR, CEARE y CTD). Cuadernos de Psicología del Deporte, 12(1), 163-166. doi:10.4321/S1578-84232012000100019

Bratland-Sanda, S. \& Sundgot-Borgen J. (2012). Eating disorders in athletes: overview of prevalence, risk factors and recommendations for prevention and treatment. European Journal of Sport Science, 13(5), 499-508. doi:10.1080/17 461391.2012 .740504

Fortes, L. S., Almeida, S. S., \& Ferreira, M. E. C. (2012). Processo maturacional, insatisfação corporal e comportamento alimentar inadequado em jovens atletas. Revista de Nutrição, 25(5), 575-586. doi:10.1590/S1415-52732012000500003

Fortes, L. S., Almeida S. S., \& Ferreira, M.E.C. (2013). Influência da ansiedade nos comportamentos de risco para os transtornos alimentares em ginastas. Revista Brasileira de Atividade Física e Saúde, 18(5), 546-553. doi:10.12820/ rbafs.v. $18 \mathrm{n} 5 \mathrm{p} 546$

Fortes, L. S., Almeida, S. S., \& Ferreira, M. E. C. (2014). A internalização do ideal de magreza afeta os comportamentos alimentares inadequados em atletas do sexo feminino da ginástica artística? Revista da Educação Física, 25(2), 181191. doi:10.4025/reveducfis.v25i2.21866

Fortes, L. S. \& Ferreira, M. E. C. (2011). Comparação da insatisfação corporal e do comportamento alimentar inadequado em atletas adolescentes de diferentes modalidades esportivas. Revista Brasileira de Educação Física e Esporte, 25(4), 707-16. doi: 10.1590/S1807-55092011000400014

Fortes, L. S. \& Ferreira, M. E. C. (2014). Comportamentos de risco para transtornos alimentares em atletas: associação com diversas características. Avaliação Psicológica, 13(1), 11-18.

Fortes, L. S., Filgueiras, J. F., Neves, C. M., Almeida, S. S., \& Ferreira, M. E. C. (2014). Efeitos do estado de humor sobre os comportamentos alimentares inadequados de atletas de atletismo. Psicologia: Teoria e Pesquisa, 30(3), 299-305. doi:10.1590/S0102-37722014000300007

Fortes, L. S., Neves, C. M., Filgueiras, J. F., Almeida, S. S., \& Ferreira, M. E. C. (2013). Body dissatisfaction, psychological commitment to exercise and eating behavior in young athletes from aesthetic sports. Revista Brasileira de Cineantropometria \& Desempenho Humano, 15(6), 695-704. doi:10.5007/1980-0037.2013v15n6p695

Joy, E., Kussman, A., \& Nattiv, A. (2016). 2016 update on eating disorders in athletes: A comprehensive narrative review with focus on clinical assessment and management. British Journal of Sports Medicine, 50(3), 154-162. doi: 10.1136/ bjsports-2015-095735

Jürgensen, L. P., Padovani, R. C., D'Avila Lourenço, L. C., Daniel, N. V. S., \& Juzwiak, C. R. (2014). Investigação da autoimagem corporal de atletas de sexo masculino. Revista Brasileira de Ciências do Movimento, 22(4), 104-104 (DOI INEXISTENTE)

Juzwiak, C. R. \& Ancona-Lopez, F. (2004). Evaluation of nutrition knowledge and dietary recommendations by coaches of adolescent Brazilian athletes. International Journal of Sport Nutrition and Exercise Metabolism, 14, 222-235. doi:10.1123/ijsnem.14.2.222

Krentz, E. M. \& Warschburger, P. (2011). Sports-related correlates of disordered eating in aesthetic sports. Psychology of Sport and Exercise, 12(4), 375-382. doi:10.1016/j.psychsport.2011.03.004 
Krentz, E. M. \& Warschburger, P. (2013). A longitudinal investigation of sports-related risk factors for disordered eating in aesthetic sports. Scandinavian Journal of Medicine \& Science in Sports, 23(3), 303-310. doi:10.1111/j.16000838.2011.01380.x

Lavender, J. M. \& Anderson, D. A. (2010). Contribution of emotion regulation difficulties to disordered eating and body dissatisfaction in college men. International Journal of Eating Disordered, 43(4), 352-357. doi: 10.1002/eat.20705

Macht, M. (2008). How emotions affect eating: A five-way model. Appetite, 50(1), 1-11. doi: 10.1016/j.appet.2007.07.002

Martínez Sanz, J. M., Urdampilleta, A., Micó, L., \& Soriano, J. M. (2012). Aspectos psicológicos e sociológicos da alimentação de esportistas. Cuadernos de Psicología del Desporte, 12(2), 39-48. doi:10.4321/S157884232012000200005

Mela, D. J. (2001). Determinants of Food Choice: Relationships with obesity and weight control. Obesity Research, 9 , 249-255. doi:10.1038/oby.2001.127

Minayo, M. C. S. (2014). O desafio do conhecimento: pesquisa qualitativa em saúde (14. ed.). São Paulo, SP: Hucitec. (DOI INEXISTENTE)

Neves, C. M., Meireles, J. F. F., Carvalho, P. H. B., \& Ferreira, M. E. C. (2015). Insatisfação corporal e comportamento alimentar em atletas de esportes estéticos: uma revisão. Pensar a Prática, 18(4), 922-936. doi:10.5216/rpp.v18i4.37389

Paracampo, C. C. P., Reis, A. A., \& Teixeira, E. R. (2005). Auto-regras como variáveis facilitadoras na emissão de comportamentos autocontrolados: o exemplo do comportamento alimentar. Interação em Psicologia, 9(1), 57-64. (DOI INEXISTENTE)

Pelly, F. E., Burkhart, S. J., \& Dunn, P. (2018). Factors influencing food choices of athletes at international competition events. Appetite, 121, 173-178. doi:10.1016/j.appet.2017.11.086

Rodrigues, L., Dias, C., Corte-Real, N.,\& Fonseca, A. M. (2014). Conceito de força psicológica na Ginástica Artística: A percepção de treinadores brasileiros de elite. Revista Portuguesa de Ciências do Desporto, 14(2), 47-54. doi:10.5628/ rpcd.14.02.23

Segato, L. (2009). Humor, estresse e perfil nutricional de atletas de alto nível de vela em competição pré-olimpica. (Dissertação de mestrado). Recuperado de: http://www.dominiopublico.gov.br/pesquisa/DetalheObraForm.do? select action=\&co_obra $=156475$. (DOI INEXISTENTE)

Silva, L. \& Gomes, R. (2012). Desordens alimentares no desporto: situação atual e perspectivas futuras no estudo dos fatores psicológicos. Psicologia Clínica, 24(11), 83-100. doi:10.1590/S0103-56652012000200007

Tan, J., Bloodworth, A., McNamee, M., \& Hewitt, J. (2014). Investigating eating disorders in elite gymnasts: conceptual, ethical and methodological issues. European Journal of Sport Science, 14(1), 60-68. doi:10.1080/17461391.2012.7 28632

Troisi, J. D., Gabriel, S., Derrick, J. L., \& Geisler, A. (2015). Threatened belonging and preference for comfort food among the securely attached. Appetite, 90,58-64. doi:10.1016/j.appet.2015.02.029

Tsukamoto, M. H. C. \& Knijnik, J. D. (2008). Ginástica Artística e representações de masculinidade no Brasil. Revista Mackenzie de Educação Física e Esporte, 7(3), 111-118. (DOI INEXISTENTE)

Weinberg, R. S. \& Gould, D. (2017). Fundamentos da Psicologia do Esporte e do Exercício (6. ed.). Porto Alegre: Artmed. (DOI INEXISTENTE)

Witt Huberts, J., Evers, C., \& Ridder, D. (2014). Thinking before sinning: reasoning processes in hedonic consumption. Frontiers in Psychology, 5, 1-6. doi:10.3389/fpsyg.2014.01268

\footnotetext{
Dados dos autores:

Anna Vitoria Rodrigues Renaux de Oliveira - Mestre,Universidade Federal de São Paulo, Campus Baixada Santista.

Claudia Ridel Juzwiak - Doutora, Universidade Federal de São Paulo, Campus Baixada Santista.

Ricardo da Costa Padovani - Doutor, Universidade Federal de São Paulo, Campus Baixada Santista.
}

Endereço para correspondência:

Anna Vitoria Rodrigues Renaux de Oliveira

Universidade Federal de São Paulo

Rua Silva Jardim, 136, sala 215

11015-020, Santos, SP, Brasil

E-mail: annavrenaux@gmail.com

Recebido em:13/10/2017.

Aceito em: 20/8/2018.

Publicado em: 09/05/2019. 